\title{
Interseccionalidad y resistencia en Río Azul: mujeres migrantes organizadas en la Asociación Enlaces Nicaragüenses
}

\section{Anna Matteucci Wo Ching ${ }^{1}$}

Recepción: 29 de enero de 2018 / Aceptación: 3 de julio de 2018

\section{Resumen}

En la comunidad de Río Azul, ubicada en la Unión de Cartago, Costa Rica, existe una organización de mujeres migrantes nicaragüenses llamada Asociación Enlaces Nicaragüenses, sobre la cual se desarrolla una investigación cualitativa para comprender las dinámicas que la articulan, así como el problema medular en torno al cual se organizan estas mujeres. Para el presente artículo se plantea un análisis de los datos con base en entrevistas, observación participante en su hogares, reuniones, talleres y actividades públicas, revisión de documentos de la organización para comprender, desde el punto de vista de las migrantes que participan en la investigación la razón de ser de su organización o para qué se organizan. Entre los resultados más destacados se deduce que esta organización funciona como espacio de empoderamiento a través de la información y la formación en cuanto a derechos laborales y migratorios. La organización actúa también como espacio de encuentro cultural entre mujeres y sus familias, y como lugar de participación política y ejercicio de ciudadanía, independientemente del estatus migratorio en Costa Rica.

\section{Palabras clave}

Nicaragüenses; organización comunitaria; participación política; Río Azul; migraciones

\section{Abstract}

In the community of Río Azul, located in la Union of Cartago, Costa Rica, there is an organization of Nicaraguan migrant women called Asociación Enlaces Nicaragüenses, on which a qualitative research is developed to understand the dynamics that articulate it, as well as the core problem around which these women are organized. For the present article an analysis of the data is proposed based on interviews, participant observation in their homes, meetings, workshops and public activities, review of documents of the organization to understand, from the point of view of the migrants that participate in the research the raison d'être of your organization or what they are organized for. Among the most outstanding results, it can be deduced that this organization functions as an empowerment space through information and training regarding labor and migratory rights. The organization also acts as a space for cultural encounters between women

1 Costarricense. Licenciada en Psicología por la Universidad de Costa Rica (UCR). Investigadora en el INAMU. Correo electrónico: annamatteucci.w@gmail.com 
and their families, and as a place for political participation and exercise of citizenship, regardless of the migratory status in Costa Rica.

\section{Keywords}

Nicaraguans; community organization; political participation; Río Azul; migrations

\section{Resumo}

Na comunidade de Rio Azul, localizada na União de Cartago, Costa Rica, existe uma organização de mulheres migrantes nicaraguenses chamada Associação Enlaces Nicaraguenses, sobre a qual é desenvolvida uma pesquisa qualitativa para compreender as dinâmicas que a articulam, bem como o problema central em torno do qual essas mulheres se organizam. Para este artigo, analisa-se dados com base em entrevistas, observação participante em suas casas, reuniões, oficinas e atividades públicas, revisão de documentos da organização para entender, do ponto de vista das migrantes envolvidas nessa pesquisa, a razão de ser da sua organização ou para que elas se organizam. Entre os resultados mais notáveis, pode-se deduzir que essa organização funciona como um espaço de capacitação por meio de informações e treinamento sobre direitos trabalhistas e migratórios. A organização também atua como espaço para encontros culturais entre mulheres e suas famílias e como lugar de participação política e exercício da cidadania, independentemente do status migratório na Costa Rica.

\section{Palavras chave}

Nicaragüenses; organização comunitária; participação política; Río Azul; migrações

\section{Introducción}

Los cambios en la estructura global han generado transformaciones relevantes en los flujos migratorios internacionales, visibilizando una importante feminización de los procesos migratorios en América Latina y el Caribe, ante la creciente demanda de servicios de cuidado, base invisible del sistema económico: "Las personas se mueven, el trabajo en el sector de cuidados se internacionaliza. Así se constituyen las llamadas cadenas globales de cuidados, entrelazamientos de hogares en distintos lugares del mundo que se transfieren cuidados de unos a otros" (Pérez, 2009, p. iii). Si bien las mujeres han estado presentes desde siempre en los procesos migratorios, resulta particular que en los últimos 40 años sea más común que estas crucen las fronteras de forma independiente, es decir, sin que medie en su movilización una relación de "dependencia" familiar o de pareja (Paiewonsky, 2007). Es pertinente preguntarse entonces, qué pasa con estas mujeres migrantes al llegar al país de destino. Las mujeres nicaragüenses entrevistadas en Río Azul para el presente proceso de investigación, mencionan un antes y un después en sus vidas desde que se integraron a los procesos colectivos de la Asociación Enlaces Nicaragüenses, donde el antes estuvo marcado por la incertidumbre y el desconocimiento de sus derechos, y el después ha significado la construcción 
de poder desde abajo y el ejercicio de ciudadanía, de manera independiente sin importar su estatus migratorio en Costa Rica.

Para este artículo, se parte de los hallazgos de una investigación que gira en torno a un grupo de mujeres nicaragüenses que migraron a Costa Rica por motivos económicos, y que se han organizado des de la comunidad de Río Azul a través de la Asociación Enlaces Nicaragüenses. La asociación se concibe como un espacio colectivo construido por mujeres migrantes trabajadoras, provenientes de diversas zonas de Nicaragua, con necesidades específicas en torno a información sobre derechos laborales, trámites migratorios, procesos de regularización, y con el deseo de compartir en comunidad con otras mujeres nicaragüenses que luchan por lograr mejores condiciones de vida en Costa Rica, para ellas y sus familias. Las entrevistas realizadas se enmarcan en una investigación cualitativa en curso, realizada por el Instituto de Investigaciones Sociales de la Universidad de Costa Rica, llamada "Organización comunitaria de mujeres migrantes: el caso de la Asociación Enlaces Nicaragüenses de la comunidad de Río Azul". La pregunta central que guía esta investigación es cómo se articula esta organización para la participación política de mujeres migrantes nicaragüenses en Río Azul, y uno de sus objetivos es comprender el para qué se organizan de acuerdo con la perspectiva que tienen las participantes sobre el quehacer de la Asociación Enlaces Nicaragüenses.

Mi relación con la Asociación Enlaces Nicaragüenses comenzó en el año 2015, a partir de proyectos de acción social igualmente realizados por parte del Instituto de Investigaciones Sociales y es, desde entonces hasta la actualidad, que he trabajado con las mujeres que integran la asociación (Azofeifa, Caamaño y Matteucci, 2015). Sin embargo, es hasta el año 2017 que me acerco a la asociación desde un proyecto de investigación etnográfica, entendida como "una estrategia metodológica que permite obtener información empírica en el espacio en donde se desenvuelven los acontecimientos estudiados, documentar lo no documentado, permitiendo así una elaboración cualitativa del contexto estudiado" (Murillo y Martínez, 2010, p. 9).

Por medio de este proceso, pude conocer los espacios vitales de las mujeres que integran el comité organizador de la asociación, además de asistir a sus celebraciones, compartir a la hora de la comida, sentarme en las gradas del barrio con los niños y las niñas; escuchar a estas mujeres me ha permitido profundizar en su historia de lucha antes y después de integrarse a la asociación.

La investigación se planteó en dos momentos, el primero corresponde al trabajo de campo realizado durante el año 2017 con cinco de las diez mujeres que integran la Asociación Enlaces Nicaragüenses, una organización civil sin fines de lucro, cuya comunidad base es Río Azul en la provincia de Cartago, mientras que la segunda fase se está desarrollando en el presente 
año 2018 con las cinco integrantes más nuevas de la agrupación. Durante las entrevistas se abordan temas diversos como los motivos que las llevaron a migrar, sus experiencias laborales en Costa Rica y el por qué y para qué se integraron a la Asociación Enlaces Nicaragüenses. Todas las entrevistas llevadas a cabo con las participantes, se basaron en una guía de preguntas previamente elaborada y fueron grabadas en audio con el consentimiento de las mujeres participantes, para posteriormente ser transcritas y analizadas a la luz de discusiones teóricas feministas.

Además de lo anterior, durante el año 2017 se hicieron sesiones de observación participante durante las reuniones de la Asociación Enlaces Nicaragüenses, así como en actividades públicas tanto dentro como fuera de la comunidad de Río Azul, entre ellas la celebración del Día de la Madre, la conmemoración del Día de la Mujer y la participación anual de Enlaces, cada primero de mayo en la marcha del Día Internacional del Trabajo, entre otras fechas de importancia para las mujeres de Enlaces. La investigación realizada busca explorar las dinámicas de la organización de estas mujeres nicaragüenses, enmarcándose en un modelo metodológico de corte etnográfico, entendido como el estudio directo de personas y grupos durante un cierto periodo de tiempo para conocer su comportamiento social (Giddens, 1994).

\section{La migración nicaragüense en Costa Rica}

Costa Rica es un receptor importante de migrantes provenientes de diversos territorios, sin embargo, el grupo poblacional extranjero más importante a nivel nacional es el nicaragüense, con una tendencia a la feminización de la migración de esta procedencia. Datos del Instituto Nacional de Estadísticas y Censos (INEC), para el año 2000, indicaron que los flujos de mujeres migrantes fue de 50,1\%, sobrepasando por primera vez los flujos de hombres migrantes, mientras que el más reciente Censo poblacional realizado en el año 2011 registró un aumento de la población nacida en el extranjero, la cual equivale al 9 \% de la población total en Costa Rica. Por su parte, datos de la Dirección General de Migración y Extranjería (DGME), para el 2011, registran que las personas que migran desde Nicaragua constituyen el $74,6 \%$ del total de migrantes residiendo en Costa Rica, representando casi 300 mil personas nicaragüenses que habitan en territorio costarricense (DGME, 2011).

Si bien Costa Rica es un lugar de origen y tránsito de la migración laboral, esta ha sido concebida históricamente como uno de los más importantes países receptores de la región centroamericana (Voorend, Rivera y Venegeas, 2013). Entre los orígenes estructurales de la migración nicaragüense hacia Costa Rica se destacan: un largo período de recesión en la economía nicaragüense que se agravó a mediados de la década de 1980 (producto del agotamiento del sector formal de la economía), la reducción del Estado durante los años noventa, el desarme de la resistencia nicaragüense, el desempleo y 
la saturación del Sector Informal Urbano de la economía (Salazar, 2001). En cuanto a las mujeres nicaragüenses, Loría (2007) escribe que su movilización a suelo costarricense toma fuerza a partir de 1990, cuando se detecta un ingreso mayor y más frecuente de mujeres provenientes de las zonas más pobres de Nicaragua (2007). Según Lerussi (2007), las razones por las que migran las mujeres son muchas; entre ellas están la búsqueda de una mejora económica, oportunidades de estudio, el anhelo de una mayor independencia, la reunificación familiar, de conocer otras realidades y experiencias, el amor, y la necesidad de huir de la violencia, aunque, como señala Loría (2007), la migración también puede ser una situación que desencadena importantes condiciones de peligrosidad, aislamiento social, exclusión, violencia y discriminación para las mujeres.

Una de las características más notables de la migración femenina a nivel internacional, es cómo esta se sustenta en la reproducción y la explotación de las desigualdades de género, ya que muchas de las mujeres que cruzan las fronteras realizan trabajos tradicionalmente concebidos como femeninos, trabajando como niñeras, trabajadoras domésticas y trabajadoras sexuales, lo cual las coloca en nichos laborales de desprotección legal y escasa remuneración (Paiewonsky, 2007). En concordancia con esta tendencia, muchas de las mujeres nicaragüenses que migran a Costa Rica se insertan en el sector de trabajo doméstico remunerado, un tipo de labor cuya historia colonial se vincula con antiguas modalidades de servidumbre basadas en jerarquizaciones étnicas que se encuentran arraigadas en la sociedad costarricense, así como en el resto de América Latina (Lerussi, 2007). Así, las mujeres migrantes nicaragüenses se insertan en el sector de trabajo que ha sido considerado como parte de un ejercicio de dominación económica, cultural y simbólica de grupos de mujeres relegadas al ámbito de lo doméstico (Lerussi, 2007), realizando una de las actividades económicas más precarias y desprotegidas a nivel jurídico y social (Bonnie, 2010). ¿De qué manera resisten las mujeres nicaragüenses ante estas condiciones de empleo y subordinación?

\section{La Asociación Enlaces Nicaragüenses: mujeres migrantes organizadas por la defensa de sus derechos}

Desde el campo de estudio de los movimientos de migrantes, autores como Varela (2015) escriben que las luchas migrantes deben ser abordadas como un nuevo campo de acción y de análisis para las ciencias sociales que piensan el disenso. El caso de la Asociación Enlaces Nicaragüenses en Costa Rica es una expresión de esta lucha protagonizada por mujeres migrantes, madres, trabajadoras domésticas remuneradas y no remuneradas, que decidieron unirse con la misión de ser "la expresión organizada de las y los migrantes para la movilización y capacitación en la defensa de sus derechos laborales, gestión en la documentación nicaragüense y costarricense. 
Y constituirse como un centro de información y de encuentro" (Enlaces Nicaragüenses, 2009).

Enlaces surge desde la informalidad, entre conversaciones de personas nicaragüenses y costarricenses, preocupadas por la fuerte estigmatización por parte de los medios de comunicación hacia personas nicaragüenses viviendo en Costa Rica (Campos y Tristán, 2009), las persecuciones policiales a migrantes que culminaron en la detención masiva que se llevó a cabo en la comunidad de la Carpio en el año 2003 (Sandoval, 2005; Sandoval et al., 2010), así como la explotación laboral (Paniagua, 2007).

Después de trabajar en actividades vinculadas a las personas migrantes en espacios como el Parque de la Merced y la Carpio, bajo el nombre Comité Migrantes de la Merced, se formaliza la Asociación Enlaces Nicaragüenses en el año 2008 mediante su inscripción legal en Costa Rica. Retomando a Varela (2015), las luchas migrantes pueden considerarse movilizaciones políticas ciudadanas protagonizadas por "no-ciudadanos", o por personas que permanecen en la clandestinidad debido a las leyes que extranjerizan a las personas "no nacionales"; en este sentido, inscribir una asociación integrada por mujeres migrantes en Costa Rica fue un reto para Enlaces. En primer lugar, debían estar regularizadas en el país para poder inscribir legalmente la asociación, pagar los servicios notariales y cumplir con la paridad de género que, en su caso, tenía que garantizar la participación del $50 \%$ de hombres en la misma, según lo establece el párrafo primero del artículo 10 de la Ley de Asociaciones, № 8901. Si bien la Asociación Enlaces Nicaragüenses cuenta con el apoyo de hombres migrantes y no migrantes en la comunidad de Río Azul, ellos rara vez asisten a las reuniones y actividades colectivas por lo que la organización en esencia es constituida por mujeres. Es razonable preguntarse si los retos de una organización migrante ante las leyes en territorio costarricense son una especie de espejo de los retos que viven diariamente las personas migrantes, ya que deben enfrentarse a los múltiples conceptos jurídicos que las colocan en el lugar de "no-ciudadanas", como escribe Varela (2015).

Una vez que lograron contar con el apoyo de hombres para la legalización de la asociación, Enlaces se inscribe y, gracias a esta vía, consigue el apoyo financiero de la Fundación Rosa Luxemburgo desde el año 2008 hasta el 2015, y del Fondo Centroamericano de Mujeres (FCAM) desde el 2008 hasta el presente. Adicionalmente a esto, Enlaces ha logrado articularse con diversas redes tanto a nivel nacional como internacional, como la Red Nacional para las Migraciones en Costa Rica, la Red Nicaragüense de Organizaciones de Sociedad Civil en Nicaragua, ambas pertenecientes a la Red Regional de Organizaciones Civiles para las Migraciones, lo cual les ha permitido insertarse en diálogos sobre el estado de los derechos de las personas migrantes tanto en Costa Rica como en la región centroamericana. "La ciudadanía de las mujeres se construye en movimiento", escribe Sánchez Olvera (2006, p. 1) 
y, desde Enlaces, mujeres migrantes nicaragüenses han logrado el ejercicio político de organizarse y asumirse como sujetos de derechos, más allá del estatus migratorio bajo el cual residen en el país.

La comunidad que convoca a la asociación es la de Río Azul, un territorio montañoso ubicado en la provincia de Cartago que, según datos del INEC (2011), es habitada por 12010 personas, de las cuales 6045 son mujeres. El territorio de Río Azul tiene una historia particular, ya que funcionó como relleno sanitario durante 34 años, entre el año 1973 y el 2007, para la recepción de alrededor de 700 toneladas de basura generadas por 12 cantones del Gran Área Metropolitana (Suárez y Zúñiga, 2013). Luego de su cierre técnico en el año 2008, persisten diversas problemáticas de mal manejo de la basura, contaminación y escasez de agua, hacinamiento y también situaciones de violencia vinculadas con el enfrentamiento entre grupos dedicados a la venta de drogas.

Las mujeres de Enlaces se reúnen, como mínimo, una vez al mes en un espacio que alquilan en el segundo piso de una casa en Río Azul. Se trata de un espacio pequeño que cuenta con una bodega donde se almacenan documentos y materiales de trabajo, una sala donde se realizan las reuniones en la que se encuentran las sillas dispuestas en forma circular, una pizarra, dos computadoras que no funcionan, y una pila donde se preparan los alimentos aunque, por lo general, no hay agua.

Actualmente, Enlaces está integrada por 10 mujeres en edades entre los 27 y los 63 años que asisten regularmente a todas las reuniones; la mayoría de ellas se encuentran indocumentadas, viviendo de trabajos temporales como empleadas domésticas en casas o fábricas, con parejas que trabajan como albañiles en el sector de la construcción, en ventas informales o seguridad privada. Algunas de las mujeres de Enlaces se encargan de sus hijos e hijas por cuenta propia o con ayuda de sus madres que les ayudan con el tema del cuido, ya que, en promedio, tienen de 3 a 4 hijos(as). Se trata de familias integradas por personas de nacionalidad nicaragüense y costarricense, por lo que se consideran familias mixtas o binacionales; cabe destacar que la organización intenta integrar a niños, niñas y adolescentes en todas las actividades y reuniones, garantizando así una mayor participación de las mujeres, ya que suelen tener dificultades para resolver el tema del cuido.

Enlaces se organiza bajo el liderazgo de Quxabel, una mujer nacida en Honduras, nacionalizada nicaragüense y residente en Costa Rica que, desde su juventud, ha sido parte de importantes luchas sociales en la región centroamericana, como en el proceso contra la dictadura de Somoza durante la década de 1970 en Nicaragua. Además de Quxabel, la organización se estructura en torno al "comité", el cual se encuentra integrado por las cinco mujeres entrevistadas durante el 2017, que corresponde al subgrupo de la asociación a quien corresponde dividir las tareas para las actividades agendadas a lo largo del año. Ellas administran tareas como preparar los alimentos, 
convocar a las demás compañeras, gestionar los espacios de reunión, entre otras. Las decisiones se toman en colectivo durante las reuniones, aunque muchas de las iniciativas son propuestas desde el liderazgo de Quxabel, quien es la única integrante de la organización con una formación universitaria, siendo esta en Economía. Las otras cinco mujeres que integran la asociación son las más jóvenes en edad, y en tiempo de integrar la organización, por lo que se trabajará durante el año 2018 (por separado) el proceso de entrevistas y visitas con ellas.

De las entrevistas realizadas en el año 2017, se desprenden dos preocupaciones fundamentales de la Asociación Enlaces Nicaragüenses: la regularización como garantía de los derechos de las personas migrantes en el país y el reconocimiento de los derechos elementales de las personas no documentadas. Entre las demandas más importantes de Enlaces se encuentran cambios vinculados con la Ley General de Migración y Extranjería (Ley $\mathrm{N}^{\circ}$ 8764), donde proponen que se haga una revisión de los costos de regularización para que estén en concordancia con los salarios que devengan las personas migrantes según sus sectores laborales. Además de la demanda anterior, Enlaces considera que es necesario y urgente que el Ministerio de Trabajo y Seguridad Social (MTSS) y la Caja Costarricense del Seguro Social (CCSS) asuman un liderazgo real que vele por el cumplimiento de los empleadores y empleadoras, en el aseguramiento de las personas migrantes que contratan. Lo anterior es clave en el acceso a servicios de las personas migrantes en Costa Rica, ya que se requiere que estén al día con el pago del Seguro Social del Estado para poder regularizarse.

En términos generales, la Asociación Enlaces Nicaragüenses ha buscado constituirse como un espacio de empoderamiento social para el ejercicio de los derechos ciudadanos de las personas migrantes nicaragüenses en ambos países. Una de sus expresiones en el espacio público más importante es su participación anual durante la marcha del Día Internacional del Trabajo, lo cual resuena con otros movimientos de migrantes sin documentos en Estados Unidos que desde el año 2006 se movilizan esta misma fecha (Johnson y Ong Hing, 2007). En este sentido, Varela (2015) plantea que las redes de migrantes se componen de núcleos organizativos que, según la coyuntura, participan en grandes movilizaciones de personas migrantes y no migrantes, y el caso de la participación de Enlaces durante el 1 de mayo es un ejemplo de esta forma de integrarse en procesos de expresión ciudadana más amplios.

\section{Interseccionalidad y resistencia: mujeres, migrantes, nicaragüenses, trabajadoras organizadas}

Rauber (2005) plantea que el capitalismo neoliberal globalizado desafía a la humanidad a pensar con urgencia en su sobrevivencia, los paradigmas dominantes de nuestra cultura y nuestro modo de vida bajo la hegemonía 
de la civilización occidental, han priorizado los valores económicos por encima de la problemática central de la transformación social. En este sentido, las organizaciones sociales como la Asociación Enlaces Nicaragüenses son una apuesta colectiva de resistencia ante las múltiples condiciones adversas como la pobreza, el desempleo y la violencia que como mujeres, migrantes nicaragüenses, y trabajadoras han enfrentado incluso antes de tomar la decisión de migrar.

Datos de la Oficina Internacional de Trabajo (OIT) del año 2003 sobre Nicaragua, indican que las mujeres constituyen el 50,8 \% de la población, y que suelen habitar en las ciudades nicaragüenses, mientras que la población masculina nicaragüense se concentra en las zonas rurales. Dicha distribución poblacional responde a que las familias en condiciones de pobreza de las zonas rurales envían a las mujeres jóvenes como fuerza laboral a las ciudades para el trabajo doméstico, siguiendo así con la tradicional división sexual del trabajo que relega sobre las mujeres las tareas vinculadas con el espacio privado: lavar, planchar, cocinar, barrer, cuidar, entre otras (OIT, 2003). Sobre los motivos que la llegaron a migrar, Rosa, una de las mujeres de Enlaces, comenta:

Yo me vine porque mi mamá la operaron y aquí no había ninguna mujer. Me mandaron un poquito de plata y el resto lo pusimos nosotros y nos vinimos. Vendimos el tele, vendimos las cositas que tenían valor y nos vinimos. Duramos dos días para llegar. Porque nos vinimos por Santa Cecilia, Santa Cruz, Santa Teresa, Tambor y todos esos lugares. Nos vinimos por detrás, porque yo podría entrar, H y V podían entrar, pero el papá, J y L no podían entrar (Rosa, comunicación personal, julio de 2017).

De igual manera, muchas mujeres nicaragüenses migran a zonas urbanas costarricenses para dedicarse al empleo doméstico que, para Larussi (2007), es un campo de trabajo subvalorado no solo por estar asociado a determinadas castas, grupos y clases sociales en situación de exclusión y desigualdad, ni por estar vinculado con elementos étnicos a los que se le han asignado el hacer este tipo de tareas, sino también por tratarse de un área de trabajo que se ha denominado reproductivo y por tanto femenino. A pesar de lo anterior, una de las mujeres entrevistadas encuentra que el horario laboral que tiene como trabajadora doméstica le permite atender a sus hijos y a sus hijas, con mayor facilidad que si trabajara en alguna empresa privada, al respecto dice:

El problema es que a mí con hijos no me sirve meterme en empresas, en una empresa a uno no le dan permiso para asistir a reuniones, en una empresa uno no puede salir si te llaman de la escuela que le sucedió algo a tu hijo, no puedes dejar el trabajo botado porque ya te corren, en cambio ahí donde yo estoy gracias a Dios la señora es muy consciente con eso, es muy accesible, porque ella: ¡no, Rosita primero están sus hijos! me da chance que los pase dejando yo entro a las 7:30, mi horario es a las 7:30, pero yo llego a las 8:30. No me ha corrido no sé por qué, porque yo llegó casi a las 8:30, porque yo paso dejando primero al de la guardia [¿se 
refiere a la guardería? De ser así se podría aclarar entre corchetes o en una breve nota a pie de página] luego el de la escuela y después ir a agarrar el bus allá abajo ya me cogió tarde, o me los llevo en el bus y ya vamos tardísimo todos, allá vamos bajando a las 7 de la mañana, por más pleito que les eche: que levántese, báñense, alístense, no hay una manera, no ha habido manera entonces ya vamos bajando las 6:45--6:57 y ya llego tardísimo (Rosa, comunicación personal, junio de 2017).

Como menciona Rosa, el del cuido de sus hijos e hijas mientras las madres trabajan es un tema relevante para todas las mujeres entrevistadas; algunas de ellas resuelven el inconveniente con guarderías, otras con abuelas y otras con las hijas mayores que se encargan de los menores, mientras las madres están fuera. El tema de cuido no es del todo fácil, Rosa cuenta que tuvo problemas para acceder a la misma porque dos de sus hijos estaban indocumentados:

fui como 3 veces ¿a dónde fue, a la guardería? No queda claro, la segunda vez me hizo llorar una señora ahí, me agarró el documento y me dijo que eso no era, que yo necesitaba tener otro tipo de documento, o sea, la cédula en mano y yo salí en llanto porque decía yo ¿ahora qué hago? entonces tengo que renunciar al trabajo ¿dónde dejo a mis hijos? no puedo, díay si renuncio ¿Cómo hago para mantener a mis hijos? ¿Cómo les voy a dar de comer? (Rosa, comunicación personal, junio de 2017).

En este sentido, las mujeres migrantes entrevistadas, lidian diariamente con la división sexual del trabajo no solo en el espacio laboral, sino también en cuanto que "los cuidados no se asumen realmente como sociales, sino como responsabilidad particular de las personas y las familias, que deben satisfacer sus necesidades en este campo de acuerdo con los recursos de que disponen" (Carcedo, Chaves y Lexartza, 2011, p. 24). De allí que la asociación y los vínculos generados entre las mujeres que la integran conforman una especie de apoyo en el tema del cuidado, donde no se responsabiliza individualmente a cada mujer por la atención de sus hijos e hijas, sino que se colectiviza como una red que sostiene la participación de las mujeres en la organización a partir de una dinámica de cuido colectivo que implica que todas están atentas a la seguridad y el bienestar de todos los niños y las niñas: se turnan para cuidarles, alimentarles, llevarles y traerles del espacio de reunión a la casa, darles materiales para que dibujen e involucrarles en los talleres junto a su madres.

En la inserción laboral de las mujeres migrantes nicaragüenses se revela que las desigualdades atraviesan múltiples categorías: etnia, clase, género, edad, nacionalidad y discapacidad, entre otras, producidas por lo que el feminismo interseccional entiende como las interacciones entre varios sistemas de subordinación (La Barbera, 2016). Costa Rica ha otorgado un lugar específico a las mujeres migrantes nicaragüenses en condiciones de vulnerabilidad, explícitamente condicionado por los permisos de trabajo que les son otorgados desde la DGME para el empleo doméstico de manera específica, reproduciendo estos sistemas de subordinación: En este sentido, Quxabel apunta en una entrevista que: 
Necesitamos cosas especiales para mujeres y sobre todo para madres jóvenes, ¿verdad? y el tema del empleo, que solo nos reconocen como dos empleos para permiso de trabajo, cuando realmente desarrollamos más de 30 trabajos, en los hoteles, en los plantíos, en las sodas... (Quxabel, comunicación personal, mayo de 2017).

La mayoría de las mujeres de la Asociación Enlaces Nicaragüenses son trabajadoras domésticas remuneradas que, si bien cuentan haber tenido experiencias laborales en otros espacios como recolectoras de café, guardias de seguridad, y trabajadoras en maquilas, tienden desde muy jóvenes a integrarse como fuerza laboral en el empleo doméstico para aportar económicamente a sus familias, tanto en Costa Rica como en Nicaragua. Al migrar a Costa Rica ya tenían familiares que les acogieron temporalmente o les ayudaron a conseguir trabajo en alguna casa, sin embargo, son frecuentes las historias de abuso por parte de empleadores y empleadoras, acoso sexual y discriminación por ser nicaragüenses. Una de las mujeres entrevistadas cuenta que estuvo trabajando para una empresa donde el empleador se valió de su condición migratoria irregular para no pagarle el salario correspondiente a ocho meses de trabajo. Otra entrevista da cuenta de una mujer que estando sola en Costa Rica se sintió vulnerada y violentada, incluso en espacios públicos, por hombres que la abordaban con falsas ofertas laborales, como la vez que un hombre le dijo a P que la iba a llevar a una entrevista de trabajo con una señora pero resultó no ser cierto, era una excusa para abordarla sexualmente:

vea es que yo quiero decirle algo, es que lo que le estoy diciendo que había un trabajo que me dijo una señora era mentira, entonces ¿por qué me hizo venir a perder mi tiempo? eso fue lo que le dije yo, me dice es que yo tengo una mejor oferta que hacerle, vea me dice, yo soy un hombre que está dispuesto a ayudarla, siempre y cuando usted colabore, yo estoy dispuesto a pagarle el cuarto y a darle la comida siempre y cuando usted me reciba en su casa. Y le digo yo: "sabe qué... se equivocó porque yo no esperaba ese tipo de ayuda con usted, yo pensé que usted era una persona más seria, no es ese el tipo de ayuda que ando buscando". No hay ningún problema, me dice, pero: "sabés una cosa", me dice, "podrás tener tus ahorros ahora para mantenerte, pero la plata se gasta y cuando vayas a necesitar plata, para pagar casa y comida acordáte de mí, ya sabés donde trabajo, yo sé que me vas a buscar porque yo sé que el hambre te va apretar..." Nunca nadie me había humillado tanto (Patricia, comunicación personal, setiembre de 2017).

La cita anterior es solo un ejemplo de algunas formas de violencia que las mujeres nicaragüenses entrevistadas expresan haber vivido, las cuales se cruzan con sus necesidades como migrantes en busca de trabajo y su situación de indocumentadas. Retomando a Paiewonsky (2007), una de las características más notables de la migración femenina es como esta se sustenta en la reproducción y la explotación de las desigualdades de género en el marco económico capitalista, en el que gran parte de las mujeres que cruzan las fronteras realizan trabajos considerados tradicionalmente como labores de mujeres, ya sea como niñeras, trabajadoras domésticas o trabajadoras sexuales, 
los cuales constituyen nichos laborales de escasa remuneración y protección legal laboral. Los sentimientos de soledad y vulnerabilidad son frecuentes en las narraciones de las mujeres entrevistadas, por lo que el espacio organizativo de la Asociación Enlaces Nicaragüenses, al cual llegaron porque alguna amiga o vecina las invitó, se convierte en una forma de resistencia que surge de una gran necesidad de informarse y buscar colectivamente un cambio significativo en la vida de las personas migrantes:

No es lo mismo estar organizada que desorganizada, para mí sobre todo por la información sobre documentación. Digamos que por medio de Enlaces se dan, digamos, por medio de esas incidencias políticas que hace $Q$ y las demás organizaciones, que al tiempo nos favorece a nosotras (Noemí, comunicación personal, julio de 2017).

...cuando yo vine aquí yo no sabía qué era violentar mis derechos; inclusive yo le trabajé a la patrona y ella estaba violentando mis derechos y yo no sabía eso, y siempre supe por mi forma de pensar que lo que ella hacía era malo, no me agradaba, pero ella estaba violentando mis derechos pero yo no lo supe. Yo empecé a enterarme que ella estaba violentando mis derechos cuando yo empecé a meterme en Enlaces Nicaragüenses (Patricia, comunicación personal, junio de 2017).

Entender la organización como una forma de resistencia es pertinente para analizar las dinámicas de la Asociación Enlaces Nicaragüenses, en especial porque las mujeres que la integran llevan consigo todas sus historias particulares de opresión y resistencia como mujeres, madres, migrantes nicaragüenses y trabajadoras, enlazando una serie de saberes que incorporan en la vida colectiva. Lugones (2011) se refiere a resistencia como ese sentido mínimo de agencia que se requiere para que la relación oprimir $\rightarrow \leftarrow$ resistir sea de tipo activo; para la autora, existe un tipo de subjetividad resistente que se expresa infra-políticamente cuando se le niega la legitimidad, la autoridad, la voz, el sentido y la visibilidad a una persona:

La infra-política marca el giro hacia dentro, en una política de resistencia, hacia la liberación, y muestra el poder de las comunidades de los oprimidos al constituir significados resistentes y al constituirse entre sí en contra de la constitución de significados y de la organización social del poder (Lugones, 2011, p. 109).

En este sentido, podría pensarse que la asociación en sí misma tiene esa subjetividad resistente, cuyas acciones apuntan a incidencia política a favor de una vida digna para las personas migrantes en Costa Rica, pero que tiene alcances limitados porque la misma asociación lucha por sostenerse y los espacios de escucha para las mujeres migrantes son escasos. Las mujeres entrevistadas plantean al menos tres motivos para organizarse desde Río Azul: el primero y más relevante para todas las entrevistadas es la información que logran adquirir sobre procesos migratorios; este conocimiento lo reconocen como una fortaleza que les permite ayudar y aportar a las personas que están en situaciones como las que ellas han vivido por falta de documentación. 
El segundo es el empoderamiento de ellas mismas como mujeres a través del aprendizaje que la organización les ha dado, la apropiación del mismo a la hora de expresarse, hablar, opinar, decir, reclamar y, sobre todo, para debatir cuando no están de acuerdo con algo. El tercer aspecto organizativo que destaca una de las entrevistadas es que las reuniones y actividades permiten crear un lazo cultural entre las mujeres nicaragüenses en Río Azul que asisten a las reuniones para celebrar sus festividades, comer sus comidas tradicionales y relacionarse como nicaragüenses, aun estando fuera de su país de origen. Entender la participación puede ser un concepto ambiguo, como explica Fassler (2007), sin embargo, esencialmente es "formar parte de" y el "accionar que involucra a otras personas con las cuales se comparten objetivos comunes" (p. 11); la participación también puede entenderse como los lazos de solidaridad que pueden darse en los procesos colectivos, como el caso de la asociación.

\section{Ciudadanas con o sin documentos}

Siguiendo a Fassler (2007), las organizaciones de la sociedad civil "se han multiplicado, expresando, por un lado, la fragmentación social y, por otra, la existencia de nuevas y viejas identidades que luchan en el espacio público por el reconocimiento de sus especificidades y la satisfacción de sus demandas" (p. 11). En ese sentido, en Costa Rica existen organizaciones de diversa naturaleza, dedicadas a la lucha por los derechos de las personas migrantes y refugiadas, entre las cuales se pueden mencionar el Centro de Derechos Sociales del Migrante (CENDEROS), el Servicio Jesuita para Migrantes Costa Rica, el Centro Internacional para los Derechos Humanos de los Migrantes (CIDEHUM), la Pastoral Social Caritas de Costa Rica, el Centro Sindical del Migrante, el Sindicato Unitario de Trabajadores de la Construcción, la Red de Jóvenes sin Fronteras, entre otras (Sandoval et al., 2012). Sin embargo, las organizaciones integradas mayoritariamente por personas migrantes son pocas. Entre ellas, Sandoval et al. (2012) enlista la Asociación de Trabajadores Nicaragüenses Unidos (ATNU), la Confederación Solidaridad, La Asociación Nicaragüenses Sin Fronteras, la Asociación Misquitos Nicaragüenses en Costa Rica, la Red de Mujeres Nicaragüenses y la Asociación Enlaces Nicaragüenses, sobre la cual se realiza el estudio en cuestión. El problema-centro que articula a la Asociación Enlaces Nicaragüenses es precisamente la lucha por el respeto a los derechos laborales de las personas migrantes y por una reforma a la ley actual migratoria,

Que venga a rebajar los costos y simplifique los trámites, ya que muchas mujeres trabajadoras tienen varios hijos, incluso son madres de niños costarricenses, pero que también tienen hermanos de nacionalidad nicaragüense. A estas mujeres se les hace difícil regularizar a la familia, ya que ellas están en el nivel más bajo de la tabla salarial, sus esposos generalmente son guardas de seguridad o trabajadores de la construcción, a quienes, además de devengar bajos salarios, el ramo en que 
laboran no entra en el permiso laboral que actualmente es otorgado por Migración (Entrevista a Quxabel, La Nueva Prensa, mayo de 2017).

Las políticas migratorias y sus trámites limitan cada vez más que personas migrantes logren integrarse realmente como personas con derechos ciudadanos en el país destino; de acuerdo con Sandoval (2007), persiste una visión reduccionista según la cual "la ciudadanía se define por la condición migratoria" (p. xv), invisibilizando y excluyendo así a personas migrantes que se encuentran indocumentadas en el país. Aunado a lo anterior, Phillips (1996) escribe que la desigualdad no solo se da en la distribución de los bienes, sino que es un contexto institucional que limita nuestra capacidad de participar y el desarrollo de nuestras propias capacidades; en este sentido, las mujeres de Enlaces luchan diariamente por la posibilidad de mejorar sus condiciones de vida en territorio costarricense.

A pesar de las condiciones adversas que hay en general para el reconocimiento de la participación de las mujeres migrantes nicaragüenses en Costa Rica, la Asociación Enlaces Nicaragüenses tiene un objetivo claro establecido en torno a la participación e incidencia política. Una de sus actividades clave es la marcha del Día Internacional del Trabajo, 1 de mayo, ya que no solo expresan públicamente el reclamo de sus derechos laborales como nicaragüenses al lado de personas trabajadoras costarricenses, sino que es la actividad más grande del año para Enlaces. Específicamente, para este día han logrado convocar alrededor de 60 personas entre las parejas de las mujeres, sus familiares, niños, niñas, adolescentes, jóvenes y demás personas de la comunidad de Río Azul que, ese día, salen a la calle como parte de la asociación. Una mujer entrevistada elabora:

nosotros salimos a celebrar el día del trabajador, porque somos trabajadoras pero también es el día de la libertad en mi forma de expresarlo; porque es el día que todas las personas migrantes pueden salir a la marcha sin temor de represalia, sin temor de que haya una redada, que se lleven a toda esta gente porque andan haciendo loco en las calles (Patricia, comunicación personal, mayo de 2017).

Desde el accionar en el espacio público, la asociación rompe con la tradicional división entre el espacio público y privado que limita el accionar de las mujeres al hogar y lo reproductivo, y ejerce una forma de ciudadanía pública que se contrapone a la comprensión normativa del espacio público asociado a atributos viriles (Lerussi, 2007). Sin embargo, la importancia de repensar el poder que plantea Rauber (2000) está asociada con el replanteamiento de las relaciones entre sociedad civil y la sociedad política, además de los múltiples nexos que existen o pueden existir entre ambas dimensiones. La participación de este grupo de mujeres nicaragüenses en espacios públicos de protesta, es salir del espacio doméstico y reclamar desde su rol de trabajadoras el reconocimiento de sus derechos sin importar si tienen o no documentos. En este sentido, se puede pensar en 
ejemplo de la construcción de poder desde abajo, un concepto que recoge experiencias en que hay un ejercicio de ciudadanía de grupos que desde su espacio de acción relativamente "pequeño", apunta a lograr grandes transformaciones en pro de una vida digna (Rauber, 2000).

Si bien, desde la teoría, es posible comprender la dinámica de la asociación como un ejercicio de ciudadanía y de participación política de mujeres migrantes nicaragüenses, resulta central para la investigación conocer si las mujeres entienden como política la forma en que se han articulado, ya que Rauber (2000):

no es lo mismo ser espectador de los hechos que ser protagonista, y de lo que se trata es de que el pueblo, en sus diversos sectores, sea protagonista. Porque el proceso de lucha es, a la vez, un proceso de formación de conciencia, de constitución de actores-sujetos, de construcción, acumulación y consolidación de organización, de poder (Rauber, 2000, p. 5).

Al entrevistar a las mujeres del comité de Enlaces Nicaragüenses, les pregunté si ellas consideran que su trabajo-organización es político, algunas manifestaron que:

Tal vez no he pensado que sea algo como político, pero con el solo hecho de presentarse en un lugar y tener una reunión con varios grupos y tener la facilidad de poder hablar y expresarte y querer motivar a otras personas; yo digo que ya eso es (Patricia, comunicación personal, junio de 2017).

Quiera o no quiera, uno siempre tiene que estar en eso, aunque no se vea así pero sí está uno metiéndose en la política, aunque uno no lo quiera ver de esa manera, pero de que es política, es política (María, comunicación personal, julio de 2017).

Para mí, significa de que las organizaciones, verdad... o no solo organizaciones busquen a los gobiernos tanto el de aquí como el de allá porque, porque como extranjeros el gobierno tiene que ver por nosotros aquí, verdad, como extranjero y como migrante hay que hacer que nuestro gobierno vea por nosotros, igual, acá en el extranjero. Igual el gobierno de acá, verdad, que estamos acá, que crean leyes favorables también para, para uno. O sea, para mí qué significa: acudir a los gobiernos para que formen leyes favorables para el migrante (Noemí, comunicación personal, agosto de 2017).

Si bien algunas reconocen el carácter político de Enlaces y sus acciones, no todas parecen sentirse cómodas con el término, ya que lo asocian con personajes específicos de la política tradicional:

Nosotras no tenemos ningún político en la organización... que los políticos ni siquiera saben a veces lo que hablan, porque para poder hablar hay que ponerse en los zapatos de aquella persona, ellos se están ganando su buen salario, tienen sus documentos bien, no tienen ningún problema, en cambio la persona que no tiene documento ¿qué?, ellos no piensan eso (Rosa, comunicación personal, julio de 2017).

A nivel general, las mujeres plantean un reconocimiento de los logros de la organización como la movilización del 1 de mayo, la visita de la Dirección General de Migración y Extranjería a Río Azul (mediante la Migra-Móvil), los 
talleres y visitas de casa en casa para ofrecer información a la comunidad en materia de derechos. Asimismo, se reconoce la necesidad de que Enlaces continúe trabajando, que se mantenga viva la Asociación, ya que, como dice Noemí en una entrevista, si continúa la falta de empleo la migración no se va a detener.

Cabe preguntarse también qué es lo que se genera en términos afectivos a partir de los lazos que han sostenido a lo largo de los años siendo que ellas, además de migrantes, nicaragüenses, madres, trabajadoras, vecinas, son un colectivo de mujeres que decidieron enlazar sus historias y sus luchas. Lagarde (2006) habla sobre los pactos que se generan entre mujeres ante un sistema patriarcal que limita sus posibilidades de participación en la esfera pública: "La sororidad emerge como alternativa a la política que impide a las mujeres la identificación positiva de género, el reconocimiento, la agregación en sintonía y la alianza" (p. 25). La relación entre estas mujeres se habla desde la confianza y relaciones sinceras. Durante las entrevistas a las integrantes del comité de la Asociación Enlaces Nicaragüenses, hablamos algunos temas sobre los vínculos que se forman entre ellas como mujeres:

Yo siento que Enlaces es una familia; una familia que ha venido a sufrir, nos identificamos con lo que hemos vivido, y solo nosotras sabemos; podría hablarte de mi persona, que tal vez es el caso de mucha gente, solo nosotras como mujeres sabemos lo que hemos pasado y lo que nos ha costado llegar hasta donde hemos llegado... (Patricia, comunicación personal, mayo 2017).

Fassler (2007) explica que las mujeres buscan espacios de acción que privilegien la solidaridad por encima de la competencia y destaca que evaluaciones de algunas experiencias de participación local se convierten en un espacio de empoderamiento concluyendo que "La participación de las mujeres a nivel local es una experiencia necesaria para avanzar en la construcción de una identidad propia en la medida que fortalece a las mujeres como personas y las legitima como actores sociales" (pp. 12-13).

\section{A modo de conclusión}

La Asociación Enlaces Nicaragüenses puede considerarse una de estas experiencias que Fassler (2007) menciona, ya que las mujeres que integran la asociación se ve marcada por su trabajo en la organización, no solo por la utilidad de la información sobre trámites y documentos migratorios, sino también por la experiencia de movilizar personas a nivel local en Río Azul, de marcar una diferencia en las posibilidades de alguien con el conocimiento que ellas tienen que, además, les ha permitido desenvolverse fuera del espacio privado con un grado de poder y autonomía que quizás no hubieran desarrollado si no fuera por su trabajo como integrantes de Enlaces.

La Asociación Enlaces Nicaragüenses es una apuesta colectiva de resistencia ante las múltiples condiciones adversas que viven sus integrantes, 
como mujeres, migrantes nicaragüenses, trabajadoras y madres, en un contexto de migración femenina internacional que relega a las mujeres a sectores de laborales de desprotección legal y escasa remuneración. Ante este panorama, la posibilidad de juntarse significa para las mujeres entrevistadas el acceso a información sobre trámites migratorios y derechos humanos, lo cual se convierte en una poderosa herramienta para su sobrevivencia y la de sus familias.

Por tratarse de una organización de migrantes, Enlaces se inserta en un tipo de lucha que podría concebirse como protagonizada por personas "nociudadanas", sin embargo, ejercen ciudadanía en la práctica de reconocerse con el derecho a tener derechos, y como sujetos políticos independientemente de su estatus migratorio. Así, inciden en actividades dedicadas a la comunidad migrante en Río Azul, y accionan desde el espacio público con su participación anual en la marcha del Día Internacional del Trabajo, fecha en que expresan junto a más personas trabajadoras sus demandas particulares. Como trabajadoras domésticas remuneradas y no remuneradas, insertarse en una lucha colectiva significa salir del espacio privado, asociado al hogar y lo reproductivo, con un grado de poder y autonomía que se alimenta de la práctica organizativa.

Además, mediante la organización se genera un lazo de cuido comunitario entre las mujeres de la Asociación Enlaces Nicaragüenses, donde los niños, niñas y jóvenes se integran en todas las actividades de la organización con el fin de promover habilidades sociales como compartir, participar, opinar y escuchar. Ante la división sexual del trabajo, asumir el cuido de forma colectiva significa facilitar que más mujeres con hijos e hijas se integren a la asociación mediante un espacio seguro, particularmente necesario ante el recrudecimiento de la violencia por parte de bandas vinculadas al narcotráfico en Río Azul. De allí que se comprende el acto de organizarse por parte de las mujeres migrantes nicaragüenses de la Asociación Enlaces Nicaragüenses, como parte de una estrategia de sobrevivencia y sobre todo, de resistencia ante la opresión que viven día a día por razones de género, nacionalidad, edad y estatus migratorio.

La Asociación Enlaces Nicaragüenses es una apuesta colectiva de resistencia ante las múltiples condiciones adversas que viven sus integrantes, como mujeres, migrantes nicaragüenses, trabajadoras y madres, en un contexto de migración femenina internacional que relega a las mujeres a sectores de laborales de desprotección legal y escasa remuneración. Ante este panorama, la posibilidad de juntarse significa, para las mujeres entrevistadas, acceso a información sobre trámites migratorios y derechos humanos, lo cual se convierte en una poderosa herramienta para su sobrevivencia y la de sus familias.

Por tratarse de una organización migrante, Enlaces se inserta en un tipo de lucha que podría pensarse como protagonizada por personas "no-ciudadanas", sin embargo, ejercen ciudadanía en la práctica de reconocerse con el derecho a tener derechos, y como sujetas políticas independientemente de su estatus migratorio. Así, inciden en actividades dedicadas a la comunidad migrante en 
Río Azul, y accionan desde el espacio público con su participación anual en la marcha del Día Internacional del Trabajo, fecha en que expresan junto a más personas trabajadoras sus demandas particulares. Como trabajadoras domésticas remuneradas y no remuneradas, insertarse en una lucha colectiva significa salir del espacio privado con un grado de poder y autonomía que se alimenta de la práctica organizativa.

Además, mediante la organización se genera un lazo de cuido comunitario entre las mujeres de la Asociación Enlaces Nicaragüenses, donde los niños, niñas y jóvenes se integran en todas las actividades de la organización con el fin de promover habilidades sociales como compartir, participar, opinar y escuchar. Ante la división sexual del trabajo, asumir el cuido de forma colectiva significa facilitar que más mujeres con hijos e hijas se integren a la asociación mediante un espacio seguro, particularmente necesario ante el recrudecimiento de la violencia por parte de bandas vinculadas al narcotráfico en Río Azul. De allí que se comprende el acto de organizarse por parte de las mujeres migrantes nicaragüenses de la Asociación Enlaces Nicaragüenses, como parte una estrategia de sobrevivencia y sobre todo, de resistencia ante la opresión que viven día a día por razones de género, nacionalidad, edad y estatus migratorio.

\section{Referencias}

Azofeifa, Silvia; Caamaño, Carmen y Matteucci, Anna. (2015). Migraciones, género y subjetividad: El trabajo con población migrante en Costa Rica. Revista de Ciencias Sociales, III(145), 35-43.

Bonnie, Alexandra. (2010). Trabajadoras domésticas nicaragüenses en Costa Rica: un tortuoso camino hacia el reconocimiento. Revista Encuentro, 87, 75-88.

Carcedo, Ana; Chaves, María José y Lexartza, Larraiza. (2011). El papel de las migrantes nicaragüenses en la provisión de cuidados en Costa Rica. Santo Domingo: ONU Mujeres.

Campos, Anyelik y Tristán, Larissa. (2009). Nicaragüenses en las noticias. Textos, contextos y audiencias. San José: Universidad de Costa Rica.

Dirección General de Migración y Extranjería. (2011). Migración e Integración en Costa Rica: Informe Nacional 2011. Organización Internacional para las Migraciones-UNHCR ACNUR-Fondo de Población de las Naciones Unidas-Agencia Española de Cooperación Internacional para el Desarrollo. Recuperado de http://www.migracion.go.cr/integracion_desarrollo/ 236 Informe\%20Nacional\%20Migracion\%20e\%20Integracion\%202011.pdf 
Enlaces Nicaragüenses. (7 de agosto de 2009). Recuperado de http:// enlacesnicaraguenses.blogspot.com/

Fassler, Clara. (2007). Desarrollo de la participación política de las mujeres. En Gregorio Vidal y Arturo Guillén R. (Coords.), Repensar la teoría del desarrollo en un contexto de globalización. Homenaje a Celso Furtado (pp. 311-393). Buenos Aires: Consejo Latinoameriano de Ciencias Sociales (CLACSO).

Giddens, Anthony. (1994). The consequences of modernity. Stanford, CA: Stanford University Press.

Herrera Vargas, Mariela. (2000). Ciudadanía política de las mujeres en Costa Rica. Buenos Aires: CLACSO.

Instituto Nacional de Estadística y Censos. (2011). X Censo Nacional de Población y VI de Vivienda 2011. Recuperado de http://www.inec.go.cr/ censos/censos-2011

Instituto Nacional de Estadística y Censos. (2011). IX Censo Nacional de Población y V Censo Nacional de Vivienda 2000. Recuperado de http:// www.inec.go.cr/censos/censos-2000

Johnson, Kevin y Ong Hing, Bill. (2007). The Immigrant Rights Marches of 2006 and the Prospects for a New Civil Rights Movement. Harvard Civil Rights-Civil Liberties Law Review, 42(96), 99-138. Recuperado de http:// www.law.harvard.edu/students/orgs/crcl/vol42_1/johnhing.pdf

La Barbera, María Caterina. (2016). Interseccionalidad, un "concepto viajero": orígenes, desarrollo e implementación en la Unión Europea. Interdisciplina, 4(8), 105-122.

Lagarde y de los Ríos, Marcela. (15 de junio de 2017) Pacto entre mujeres y sororidad. Aportes para el debate. Recuperado de https://www. asociacionag.org.ar/pdfaportes/25/09.pdf

Lerussi, Romina. (2007). Trabajo doméstico y migraciones de mujeres en Latinoamérica. El caso de las nicaragüenses en Costa Rica. Punteo para un enfoque de reflexión y acción feministas. Anuario de Estudios Centroamericanos, (33-34), 183-203. Recuperado de https://revistas.ucr. ac.cr/index.php/anuario/article/view/1164

Ley de Asociaciones (Ley N²18). (1939, 8 de agosto). Recuperado de https:// fome.ucr.ac.cr/media/legislacion/2016/24/1._LEY_ASOCIACIONES_ N2018.pdf. 
Loría, Rocío. (2010). Vulnerabilidad a la violencia en la migración: mujeres nicaragüenses y panameñas en el tránsito migratorio. En Carlos Sandoval (Ed.). El Mito Roto. San José: Editorial de la Universidad de Costa Rica.

Lugones, María. (2011). Hacia un feminismodescolonial. La manzana de la discordia, 6(2), 105-119.

Ley General de Migración y Extranjería (Ley Nº 8764). (2009, 19 de agosto). Recuperado de http://www.migracion.go.cr/institucion/leyes\%20 migratorias/leyes/Ley\%208764\%20Migracion\%20y\%20Extranjeria.pdf

Mora, Rolando y Mora, Raúl. (2003). Reseña histórica del relleno sanitario de Río Azul y consideraciones sobre los metales pesados tratados en él y los presentes en nuestros hogares. Revista Reflexiones, 82(2), 47-58.

Oficina Internacional del Trabajo (OIT). (2003). Diagnóstico Género y Mercado Laboral En Nicaragua. Informe Final. Recuperado de http://www.paho. org/nic/index.php?option=com_docman\&view=download\&category_ slug=publicaciones-anteriores\&alias=246-diagnostico-genero-y-mercadolaboral-en-nicaragua-oit\&ltemid=235

Paiewonsky, Denise. (2007). Feminización de la Migración. Santo Domingo: Instituto Internacional de Investigaciones y Capacitación de las Naciones Unidas para la Promoción de la Mujer (UN-INSTRAW). Recuperado de http://media.onu.org.do/ONU_DO_web/596/sala_prensa_publicaciones/ docs/0381880001387294964.pdf

Paniagua, Laura. (2007). Situación sociolaboral de la población nicaragüense en Costa Rica. Revista de Ciencias Sociales, 117-118(III-IV), 57-71.

Pérez, Amaia. (2009). Miradas globales a la organización social de los cuidados en tiempos de crisis I: ¿qué está ocurriendo? Santo Domingo: UN-INSTRAW.

Phillips, Anne. (1996). ¿Deben las feministas abandonar la democracia liberal?. En Carmen, Castells (Coord.) Perspectivas feministas en teoría política (pp. 79-98). Buenos Aires: Paidós.

Rauber, Isabel. (2000). Construcción de poder desde abajo. Claves para una nueva estrategia. Ensayos. Recuperado de http://www.rebelion.org/ docs/4808.pdf

Rauber, Isabel. (2005). Movimientos sociales, género y alternativas populares en Latinoamérica y El Caribe. Ginebra: Instituto Universitario de Estudios del Desarrollo (IUED).

Sánchez Olvera, Alma Rosa. (2006). El feminismo en la construcción de ciudadanía de las mujeres en México. Recuperado de http:// 
catedraunescodh.unam.mx/catedra/CONACYT/03_Curso_PGJ/ Contenidos/contenidos/Modulo_4/2_Alma\%20Rosa\%20Sanchez.pdf

Salazar, Mariano. (2001). Panorámica de la inmigración nicaragüense en Costa Rica. San José: YMPIME-IPF-CENDEROS-CEP/ALFORJA.

Sandoval, Carlos. (2007). El Mito Roto. San José: Editorial de la Universidad de Costa Rica.

Sandoval, Carlos; Brenes, Mónica y Paniagua, Laura. (2010). La dignidad vale mucho. Mujeres nicaragüenses forman derechos en Costa Rica. San José: Editorial de la Universidad de Costa Rica.

Sandoval, Carlos; Brenes, Mónica; Paniagua, Laura y Masís Fernández, Karen. (2010). Un país fragmentado. La Carpio: comunidad, cultura y política. San José: Editorial de la Universidad de Costa Rica.

Sandoval García, Carlos. (2015). No más muros: exclusión y migración forzada en Centroamérica. San José: Editorial de la Universidad de Costa Rica.

Voorend, Koen; Rivera, Francisco y Venegas, Karla. (2013). Nicaragüenses en el Norte: Condiciones laborales y prácticas de contratación de hombres y mujeres migrantes en la Región Huetar Norte. San José: OIT. Recuperado de http://www.ilo.org/wcmsp5/groups/public/---americas/---ro-lima/--sro-san_jose/documents/publication/wcms_230811.pdf 